\title{
Perspectivas de carreira de jovens do ensino médio de escolas públicas: transgressão ou reprodução das condições sociais?
}

\author{
HeLIANI BeRLATo ${ }^{1}$ \\ LUCIANO MENDES ${ }^{1}$ \\ DANILO ANDRETTA ${ }^{1}$
}

1 Universidade de São Paulo (USP) / Escola Superior de Agricultura “Luiz de Queiroz", Programa de Pós-graduação em ADMINISTRAÇÃO, PIRACICABA - SP, BRASIL

\begin{abstract}
Resumo
O objetivo deste artigo foi analisar as perspectivas de carreiras dos jovens do ensino médio público de uma cidade do interior de São Paulo, no que tange aos aspectos sociais, familiares, educacionais e culturais. Para tanto, discutiu-se a carreira a partir de duas perspectivas: o sucesso e as indecisões inerentes a ela. Uma contribuição do artigo foi trazer para a discussão de carreira a teoria do sociólogo francês Pierre Bourdieu, que discute os limites do sistema educacional para a contribuição na carreira dos indivíduos. Realizou-se uma pesquisa quantitativa com 3.287 alunos do ensino médio de escolas públicas em uma cidade no interior do Estado de São Paulo. Após a coleta, os dados foram analisados a partir da Análise Fatorial Exploratória e da Análise de Agrupamentos. Foram encontrados seis agrupamentos de jovens do ensino médio das escolas públicas pesquisadas. Em termos de resultados, as diferenças que permitiram a constatação desses grupos foram mais vinculadas às reproduções familiares e das classes sociais do que necessariamente ao papel exercido pela escola.
\end{abstract}

Palavras-chave: Bourdieu. Carreira. Classe social. Jovens.

Career prospects for young people in public high schools in Brazil: transgression or reproduction of social conditions?

\begin{abstract}
This article aims to analyze young people's career prospects in public high schools in a city in the state of São Paulo, considering social, family, educational, and cultural aspects. Career was discussed from two perspectives: career success and career indecision. The article contributes to career discussions by bringing the theory of French sociologist Pierre Bourdieu, who investigates the limits of the educational system to contribute to individuals' careers. Quantitative research was carried out with 3,287 high school students from public schools in a city in the state of São Paulo. After collection, the data were analyzed using exploratory factor analysis and cluster analysis. Six clusters of high school youths from the public schools were found. The results showed that the differences that allowed gathering these clusters were linked to family and social class reproductions more than to the role played by the school.
\end{abstract}

Keywords: Bourdieu. Career. Social class. Young people.

Perspectivas de carrera para los jóvenes de la escuela secundaria pública en Brasil: ¿transgresión o reproducción de las condiciones sociales?

\section{Resumen}

El objetivo de este artículo fue analizar las perspectivas de carrera de los jóvenes de la escuela secundaria pública en una ciudad del interior de São Paulo, con respecto a los aspectos sociales, familiares, educativos y culturales. Para ello, la carrera se discutió desde dos perspectivas: el éxito y la indecisión. inherentes a ella Una contribución del artículo fue llevar la teoría del sociólogo francés Pierre Bourdieu a la discusión sobre la carrera, que analiza los límites del sistema educativo para la contribución a la carrera de las personas. Se realizó una investigación cuantitativa con 3.287 estudiantes de secundaria de escuelas públicas en una ciudad del estado de São Paulo. Después de la recolección, los datos se analizaron mediante el análisis factorial exploratorio y el análisis de conglomerados. Se encontraron seis grupos diferentes de jóvenes de secundaria de las escuelas públicas encuestadas. En términos de resultados, las diferencias que permitieron la constatación de estos grupos estaban más vinculadas a las reproducciones familiares y de clase social que necesariamente al papel desempeñado por la escuela.

Palabras clave: Bourdieu. Carrera. Clase social. Jóvenes. 


\section{INTRODUÇÃO}

O caráter interdisciplinar atribuído aos estudos sobre carreira justifica as várias perspectivas que a teoria sobre carreiras apresenta (HALL, 2002; ARTHUR, 1994). Essa participação das diversas áreas de estudo é expressiva para a construção do que se entende como carreira na ótica contemporânea (HARRINGTON e HALL, 2007). Três perspectivas sobre carreira tiveram destaque nos últimos anos, sendo elas: carreira sem fronteira, carreira inteligente e carreira pós-corporativa. A primeira perspectiva coloca a carreira como um processo individual e não organizacional, com um sujeito ativo nas determinações de sua carreira e não passivo em suas escolhas (ARTHUR, 1994). A segunda perspectiva tem como foco o autoconhecimento e a autoconsciência, no sentido de uma busca constante do indivíduo para os conhecimentos necessários no desenvolvimento de suas ações (DEFILLIPI e ARTHUR, 1994). Por fim, a última perspectiva posiciona-se a partir da constatação sobre a fluidez e a flexibilidade das relações de trabalho, estabelecendo a carreira também de uma perspectiva individual, mas focada nas mudanças que o indivíduo deve passar para se adaptar ao mundo em transformação (PEIPERL e BARUCH, 1997).

A carreira pode ser conceituada como uma sequência de experiências de trabalho de uma pessoa ao longo do tempo (ARTHUR, HALL e LAWRENCE, 1989), o que evidencia duas vertentes fundamentais para essa compreensão. A primeira é da carreira subjetiva, ligada à compreensão que o indivíduo tem sobre sua carreira e sobre o que ele está se tornando. A segunda é da carreira objetiva, ligada às posições sociais, às promoções e ao status, servindo para medir a trajetória profissional do indivíduo. Assim, fica visível que não é possível desarticular a carreira subjetiva da carreira objetiva, mostrando que um elemento importante está justamente na forma como as posições sociais, as promoções e o status são idealizados e buscam ser conquistados. Isso faz com que o sucesso na carreira assuma uma discussão importante no âmbito das teorias sobre carreira (ARTHUR, KHAPOVA e WILDEROM, 2005).

Remeter-se ao sucesso na carreira é considerar que as influências na escolha dela são vistas a partir das perspectivas subjetiva (escolhas, motivações, satisfação) e objetiva (salário atrativo, número de promoções, posição social). O sucesso na carreira pode ser definido como a realização de resultados desejáveis relacionados ao trabalho em qualquer momento da experiência de um indivíduo. Com isso, o sucesso na carreira é visto como algo desejável (subjetivo) pelo indivíduo e também como algo capaz de gerar prosperidade (objetivo) através das comparações sociais. Essas condições subjetivas e objetivas no sucesso na carreira são tão imbricadas que a existência de uma está diretamente relacionada à outra. Isso porque o sucesso subjetivo na carreira é conceituado como a apreensão interna do indivíduo a partir das dimensões externas (renda, segurança no trabalho, status, progressão, acesso ao ensino) que são importantes para ele. E o sucesso objetivo na carreira é conceituado como uma dimensão externa (ocupação, situação familiar, renda, nível de emprego) que delineia a situação da carreira de um indivíduo (ARTHUR, KHAPOVA e WILDEROM, 2005).

Dito isso, fica visível que a carreira, apesar de ser vista como a sequência de trabalhos de um indivíduo, depende da visão positiva ou não que o indivíduo possui sobre sua trajetória profissional e também das condições sociais e das possibilidades sobre essa carreira. Essas discussões têm marginalizado as barreiras e dificuldades enfrentadas pelos indivíduos na condução de suas carreiras, como as situações de desemprego (THOMPSON, DAHLING, CHIN et al., 2017), as mudanças na atuação profissional, a idade (NEWMAN, 1995) e as limitadas oportunidades de emprego e renda (SUTIN, COSTA JUNIOR, MIECH et al., 2009). Além disso, o acesso ao sistema de ensino (médio e superior), capaz de alavancar a carreira na condição objetiva, e as distinções entre classes sociais (status, posição social), podem ser fatores limitantes para a obtenção do sucesso na carreira, pois, ao mesmo tempo que revela um cenário de perspectivas de carreiras, condiciona os desejos dos indivíduos às suas condições sociais, que se orientam subsidiadas nessa vertente objetiva (CONNOLLY e HEALY, 2004).

Diante desse influenciador objetivo, que atua diretamente no modo como os jovens concebem suas perspectivas de carreira, alguns estudos sobre carreira têm sido desenvolvidos com aqueles que ainda não estão no mercado de trabalho (ROGNSTAD, AASLAND e GRANUM, 2004) ou que ainda se encontram no início da atividade profissional, a fim de observar possíveis configurações dentro dessas perspectivas (AKKERMANS, BRENNINKMEIJER, SCHAUFELI et al., 2015). Nessa linha, tais estudos têm focado temas como as "perspectivas sobre carreira" (CLARK, JOUBERT e MAUREL, 2017), as "escolhas sobre carreiras" (ZELLWEGER, SIEGER e HALTER, 2011) e as "indecisões sobre carreiras" (DENAULT, RATELLE, DUCHESNE et al., 2019). Os estudos são conduzidos, na maioria, com estudantes, mostrando que o sistema de ensino (fundamental, médio e superior) é de central importância para o alcance e o desenvolvimento da carreira (WRIGHT, JENKINS-GUARNIERI e MURDOCK, 2008). 
Um dos poucos estudos desenvolvidos nessa linha é o de Gale e Parker (2015). Estes autores avaliaram que as escolhas de carreiras por estudantes da classe baixa (popular) do ensino médio na Austrália passavam pelas aspirações de estarem no ensino superior. Os autores chegam à conclusão de que, apesar de haver um nível de agenciamento desses estudantes de classe baixa, que ocorre mais nas relações sociais do que nos determinantes históricos, ainda assim existem limites estruturais que impedem que eles tenham acesso ao ensino superior e sucesso nas escolhas da carreira. Para os jovens de classe baixa que conseguem alcançar o ensino superior em países desenvolvidos, a realidade também não é promissora. No estudo realizado por Lehmann (2012) com jovens universitários canadenses de classe baixa (trabalhadora), fica evidente a dificuldade que eles têm de se adaptar ao habitus universitário. Isso porque o sistema de ensino superior no Canadá é dominado por jovens de classe média, o que exige daqueles de classe baixa uma constante negociação. Lehmann (2012) conclui que essa negociação, por exemplo, permite maior adaptação dos jovens de classe baixa quando esses possuem claras suas escolhas de carreira. Mesmo que alguns consigam se adaptar ao habitus universitário, as chances de sucesso na carreira ainda são limitadas.

Foi a partir dessas constatações, de que há uma relação próxima entre carreira e sistema educacional, de que o desenvolvimento na carreira é distinto para jovens de classes sociais diferentes e de que há possíveis habitus nos sistemas de ensino (fundamental, médio e superior), que este artigo foi constituído. De modo semelhante ao trabalho de Gale e Parker (2015), a pesquisa realizada neste artigo foi com jovens do ensino médio de escolas públicas em uma cidade no interior de São Paulo. Assim, o objetivo aqui é analisar as perspectivas de carreiras dos jovens do ensino médio público de uma cidade do interior de São Paulo, no que tange aos aspectos sociais, familiares, educacionais e culturais.

Os próximos tópicos tratam, inicialmente, das contribuições de Bourdieu para os estudos sobre carreira. Vale salientar que a ênfase será dada na teoria de Bourdieu, e não em uma exploração profunda das teorias sobre carreira. Em seguida, serão apresentados os aspectos metodológicos da pesquisa realizada. Após esse percurso metodológico, serão apresentados e analisados os resultados da pesquisa sob o olhar da teoria de Bourdieu. Por fim, algumas considerações finais.

\section{As contribuições de Bourdieu para os estudos sobre carreira}

Para iniciar a aproximação das perspectivas de carreira da Sociologia da Educação de Bourdieu, é importante inicialmente compreender o contexto do desenvolvimento da teoria desse autor. Bourdieu começa a formular sua Sociologia da Educação na década de 1960 e conduz a uma revolução na forma de ver a educação e o sistema educacional (NOGUEIRA e NOGUEIRA, 2002). Isso porque até então a ideologia educacional observava esse sistema como uma forma meritocrática e republicana de entender o ensino. Nessa linha, a escola permitiria acesso igual para todos, minimizando ações que gerassem qualquer tipo de discriminação (VALLE, 2013). Essa ideologia educacional permitiu uma expansão rápida dos sistemas de ensino (inicialmente, fundamental e médio; posteriormente, superior). Na década de 1960, a França presenciava a expansão e a massificação do "secundário" (no Brasil, ensino médio) que não minimizou a condição de desigualdade social. Bourdieu (1986) observa que isso aconteceu porque a escola passou a ser um sistema de reprodução das condições sociais e nunca um sistema capaz de fazer imperar os conteúdos escolares que diminuiriam as desigualdades sociais. Tal fato se deve à escola acabar reproduzindo elementos que possuem valores das classes sociais, e nunca do sistema educacional. Bourdieu e Paresson (1975) exemplificam isso ao salientar que o professor considera pejorativo adjetivos como "escolar" em oposição ao "talento", pois este último está ligado a um capital cultural herdado.

Em relação ao capital cultural, Bourdieu (1986) avalia o papel da família e das classes sociais, que permitem elementos interiorizados (maneiras de ver o mundo e de degustar um vinho, por exemplo), objetivados (posse de uma biblioteca e de obras de artes) e institucionalizados (obtenção de um diploma reconhecido pelo Estado). Riutort (2008) avalia que essa reprodução no âmbito da escola cria um processo de "aculturação" das classes populares, na medida em que essas classes não possuem capital cultural legítimo. Tal reprodução das classes dominantes no sistema de ensino é tão forte que, salienta Bourdieu (1986), um filho de operário que passou pela escola e se tornou operário foi porque não tinha as credenciais de um "bom aluno".

Essa forma de reprodução é mais compreensível a partir das discussões de Bourdieu (1989) sobre o conceito de habitus. Como habitus, Bourdieu (1989) entende que é um sistema de esquemas individuais, socialmente constituído de disposições estruturadas (no social) e estruturantes (na mente), adquirido nas experiências práticas. A teoria do habitus de Bourdieu permite articular e conciliar indivíduo e sociedade, evidenciando que o conhecimento é obtido, inicialmente, no meio familiar (familiaridade), no meio social (objetivista) e no meio prático (praxiológico). Este último é produzido "nas relações dialéticas 
entre as estruturas e as disposições estruturadas nas quais elas se atualizam e tendem a reproduzi-las" (BOURDIEU, 1983, p. 47). O habitus é uma subjetividade socializada (BOURDIEU, 1992).

Essa breve explanação do conceito de habitus evidencia como o sistema escolar reproduz as desigualdades sociais e gera um nível de meritocracia para as classes dominantes. Assim, Bourdieu e Paresson (1975) trabalham, na análise do sistema escolar, além do capital cultural herdado, também o capital econômico e social. A partir das experiências de êxito e fracasso vividas pelo indivíduo, por membros da família e pelo grupo social próximo, começa a se formar o que é possível ou não de ser alcançado, inclusive no próprio sistema educacional. Bourdieu e Paresson (1975) observam que, para as classes economicamente superiores, os investimentos educacionais não são tão intensos quanto são para a classe média, pois esta última procura alçar posições sociais através da certificação escolar. Outro problema, salientam Bourdieu e Paresson (1975), está ligado à massificação do ensino, que tende a desvalorizar os diplomas escolares e a estimular atributos das classes dominantes que transcendem aqueles de acesso das classes populares.

A teoria dos capitais é central para a análise do sistema escolar desenvolvido por Bourdieu e Paresson (1975), pois a partir dela é possível compreender as desigualdades e as diferenças de classes no acesso a esse sistema. O capital econômico integra os bens econômicos e de produção (dinheiros, rendas, bens, trabalho). O capital social está ligado às redes de relações sociais primárias (família) e secundárias (grupos e classes sociais), constituindo os diversos habitus. E o capital cultural está ligado, em sua forma institucionalizada, aos títulos escolares e à importância desses títulos nas posições sociais dos agentes (BOURDIEU, 1986).

Com isso, Bourdieu e Paresson (1975) constatam três estratégias e disposições relacionadas ao sistema educacional, que estão ligadas aos investimentos econômicos e de tempo feitos pelas classes populares, pelas classes médias e pela elite. As classes populares investiriam menos nos sistemas de ensino pelo reduzido capital (econômico e cultural), mas principalmente por acreditarem que as chances de sucesso são limitadas. Além disso, pelos retornos de investimentos educacionais serem de longo prazo, as classes populares tenderiam a evitar esse tipo de gasto. As classes médias tenderiam a investir mais pesadamente na educação, almejando melhores posições sociais através do sucesso escolar. Esse grupo social tenderia a ver o futuro como uma aproximação das condições sociais vividas pela elite, além de conduzir a uma diferenciação cada vez maior das classes populares. Por fim, as elites, que investiriam menos tempo na educação formal, por terem maior capital cultural, pois esta é uma das demandas do sistema escolar, que privilegia os alunos mais "talentosos". Aqui, Bourdieu e Paresson (1975) distinguem as elites ricas em capital cultural e aquelas ricas em capital econômico. As elites mais ricas em capital cultural investem no sistema educacional para obter carreiras mais longas e prestigiadas. As elites mais ricas em capital econômico investem apenas para obter diplomas que legitimem sua posição social.

Quando deslocamos essas discussões para o contexto da educação pública no Brasil, essas formas de reproduções de classes ficam evidentes (VARGAS, 2009). No estudo realizado por Bonamino, Alves, Franco et al. (2010), que utilizaram dados quantitativos do Programa Internacional de Avaliação de Alunos (Pisa), no ano 2000 no Brasil, fica visível que há, sim, influências dos diversos capitais (social, cultural e econômico) no desempenho escolar dos estudantes. Com base na literatura, os autores criaram cinco conglomerados que levaram em consideração, por exemplo, posse de bens (econômico), recursos educacionais familiares (social) e nível de escolaridade da mãe (cultural). Bonamino, Alves, Franco et al. (2010) concluem que a posse desses capitais permite desempenhos educacionais melhores dos estudantes, mostrando que essa reprodução de classes é constatada também no sistema educacional brasileiro.

Se há essa reprodução de classes, então as perspectivas de carreiras, as escolhas sobre carreiras ou as indecisões sobre carreiras também seguem essa lógica de reprodução. É neste ponto que é possível constar, a partir da visão de Bourdieu e Paresson (1975), que as perspectivas, as escolhas ou as indecisões de carreiras para as classes baixas (populares ou trabalhadoras) não possuem o privilégio de condução das suas carreiras, por terem baixo capital social, cultural e econômico. Além disso, se o sistema educacional, que é central para o desenvolvimento de carreiras, reproduz essa distinção entre classes, então as possibilidades de desenvolvimento são limitantes para as classes baixas. É nessa linha que Bourdieu e Paresson (1975) salientam que, sendo o sistema educacional reprodutor dos capitais social, cultural e econômico das classes altas ou elites, há evidentes limitações das classes baixas em atingir posições e status superiores no mercado de trabalho. Diante dessa constatação, fica visível que os discursos sobre carreiras sem fronteiras, carreiras inteligentes e carreiras corporativas estão mais atrelados às classes altas do que permitindo acesso às classes baixas a melhores posições no mercado de trabalho. 


\section{PERCURSO METODOLÓGICO}

Esse percurso metodológico filia-se à sociologia reflexiva de Bourdieu (2002). Tal forma de fazer ciência é compreendida como uma atividade racional, mas o papel principal será de se furtar ao senso comum, conduzindo reflexões que vão além daquelas já reificadas no contexto social. Por esse motivo, empreende-se nesse estudo a reflexão do sistema educacional como reprodutor de classes. Do mesmo modo, as ideias atreladas à carreira também seguem essa reprodução, sendo muito mais constatadas nas classes altas do que nas baixas.

Com isso, as noções de campo e habitus são centrais para o método sociológico em Bourdieu (2002). Isso porque o campo gera um espaço relacional, onde os agentes e instituições se produzem e reproduzem. O campo estabelece uma relação direta entre sociedade e indivíduo, permitindo, de maneira relativamente autônoma, a existência de leis próprias que estruturam o comportamento dos agentes. É no campo que os diversos capitais (social, cultural e econômico) são utilizados, realizando distinções e relações de poder. A partir da integração dos agentes aos diversos campos é que ocorrerão as disposições duráveis que mantêm essas distinções entre agentes. É esse processo de incorporação e dos conjuntos de conhecimentos adquiridos no campo que Bourdieu (2002) chama de habitus.

Para compreender o campo e o habitus, Bourdieu utilizou de diversos métodos de pesquisa, que iam da etnografia às análises estatísticas de dados quantitativos. Como bem lembra Thiry-Cherques (2006, p. 45), a análise entre o habitus (posições e incorporações) e o campo (lógicas e estrutura) desvela-se mediante a explanação da vida social, não através de entrevistas, mas, sim, por meio de "análises estatísticas das correlações no desvelamento das estruturas profundas". Thiry-Cherques (2006) salienta que a tentativa de compreensão da hierarquia social e profissional a partir de questões do tipo "na sua opinião..." seria viciada pela doxa (senso comum). As análises estatísticas contribuem para minimizar os efeitos da doxa, evidenciando as hierarquias, as distinções e as reproduções de classes.

Constatando a importância da análise estatística para a compreensão das distinções entre classes sociais e as hierarquias nos campos, foi que se realizou uma pesquisa quantitativa, desenvolvida através de um questionário fechado com dez questões relacionadas, inicialmente, às características sociodemográficas e, na segunda etapa, com 49 assertivas em uma escala Likert de 7 pontos, que iam de "discordo totalmente" a "concordo totalmente". Como a teoria dos capitais é central na análise de Bourdieu e Paresson (1975) e também reveladora do habitus, o questionário foi constituído a partir de assertivas que representem a existência dos capitais econômico, social e cultural dos(as) estudantes participantes da pesquisa.

A pesquisa contou com a participação de 15 escolas públicas estaduais de uma cidade no interior de São Paulo, escolhidas por critério geográfico (bairros onde as escolas estão situadas) e por disponibilidade de horário e espaço nas escolas para a aplicação do questionário. Vale salientar que a pesquisa contou com o aval e a contribuição da Secretaria da Educação do município e com a aprovação no Comitê de Ética. Por esse motivo, os nomes das escolas e dos alunos foram suprimidos, pois não são informações relevantes para os propósitos da pesquisa. Das escolas pesquisadas, coletaram-se informações de alunos estudantes em período integral (4 escolas), período noturno (4 escolas) e período matutino (11 escolas), totalizando 82 salas de aula visitadas.

Ao total, aplicaram-se 3.303 questionários, dos quais 3.287 foram considerados válidos para os propósitos da pesquisa. Em comparação com o número total de alunos matriculados em escolas públicas estaduais no município pesquisado, aproximadamente 10.024 alunos, a amostra compõe-se de cerca de $33 \%$ do número de alunos nas escolas públicas no período em que a pesquisa foi realizada. Entre os respondentes, $24 \%$ declararam trabalhar e $76 \%$ declararam não trabalhar.

Para a análise da parte sociodemográfica do questionário, utilizou-se o cálculo de proporção (porcentagem) para cada variável analisada. Para a parte da escala de concordância (Likert), foram utilizadas técnicas multivariadas para análise, sendo elas a Análise Fatorial Exploratória e a Análise de Agrupamentos.

A Análise Fatorial Exploratória foi utilizada com o intuito de reduzir a quantidade de variáveis da escala a uma quantidade menor de fatores que representasse a estrutura original. O refinamento da escala levou à exclusão de alguns indicadores e à extração de seis fatores. Obteve-se um KMO de 0,798, com rejeição da hipótese nula no teste de Bartlett e 47,83\% de variância explicada, o que sugere bom ajuste do modelo fatorial.

Os fatores obtidos e que deram base para a análise de agrupamentos a posteriori foram os seguintes: Fator 1 - o ganho financeiro e o status como determinante de carreira; Fator 2 - presença da família e do trabalho como prioridade; 
Fator 3 - o estudo é importante; Fator 4 - grande incerteza sobre a escolha profissional; Fator 5 - o trabalhar é uma necessidade atual; e Fator 6 - o ensino público me discrimina. Hair, Sant'Anna, Gouvêa et al. (2009) apontam que o coeficiente Alfa é uma estimativa frequentemente aplicada, mas pode subestimar a confiabilidade. Desse modo, considerando a relevância dos fatores para a compreensão do fenômeno, manteve-se o Fator 6, pois ele revela uma condição importante sobre a forma como o ensino público de ensino médio é visto no Brasil. A Tabela 1 apresenta os fatores encontrados na análise fatorial, assim como as variáveis relacionadas aos fatores, a carga fatorial de cada uma das variáveis, o Alfa de Cronbach de cada um dos fatores e a base teórica para cada um dos fatores. Como as variáveis foram construídas a partir da teoria dos capitais, a análise fatorial e de agrupamentos revelou a predominância de um dos capitais (econômico, social e cultural) para cada um dos fatores encontrados.

Tabela 1

Indicadores de ajuste da Análise Fatorial Exploratória e os capitais econômico, social e cultural

\begin{tabular}{|c|c|c|c|c|}
\hline Fatores & Variáveis & $\begin{array}{l}\text { Carga } \\
\text { fatorial }\end{array}$ & $\begin{array}{l}\text { Alfa de } \\
\text { Cronbach }\end{array}$ & $\begin{array}{l}\text { Base teórica: } \\
\text { teoria dos capitais } \\
\text { de Bourdieu }\end{array}$ \\
\hline \multirow{6}{*}{$\begin{array}{c}\text { O ganho financeiro } \\
\text { e o status como } \\
\text { determinante de } \\
\text { carreira }\end{array}$} & A vontade de ganhar um alto salário influencia minha escolha de carreira & 0,73 & \multirow{6}{*}{0,73} & \multirow{6}{*}{ Capital Econômico } \\
\hline & Quero uma profissão que me permita comprar tudo o que eu desejar & 0,67 & & \\
\hline & Ganhar dinheiro é o que me faz buscar uma carreira & 0,67 & & \\
\hline & Se eu tiver uma carreira, com certeza irei ganhar mais dinheiro & 0,61 & & \\
\hline & Ter carreira é ter sucesso & 0,58 & & \\
\hline & Minha felicidade está na quantidade de dinheiro que vou ganhar & 0,55 & & \\
\hline \multirow{8}{*}{$\begin{array}{l}\text { Presença da } \\
\text { família e do } \\
\text { trabalho como } \\
\text { prioridade }\end{array}$} & Prefiro formar minha família antes de estudar & 0,66 & \multirow{8}{*}{0,63} & \multirow{8}{*}{ Capital social } \\
\hline & Minha escolha profissional está ligada à escolha profissional dos meus pais & 0,65 & & \\
\hline & Penso em parar de estudar para trabalhar & 0,61 & & \\
\hline & Para trabalhar, não preciso estudar & 0,48 & & \\
\hline & Prefiro fazer um curso técnico do que uma faculdade & 0,46 & & \\
\hline & Acredito que meus amigos podem influenciar minha escolha profissional & 0,44 & & \\
\hline & Não me imagino fazendo faculdade pública & 0,37 & & \\
\hline & $\begin{array}{l}\text { Abro mão de escolher a carreira que quero para não exigir de meus pais } \\
\text { aquilo que não podem dar }\end{array}$ & 0,31 & & \\
\hline \multirow{4}{*}{$\begin{array}{l}\text { O estudo é } \\
\text { importante }\end{array}$} & $\begin{array}{l}\text { Meus professores me passam o conhecimento que vou usar pelo resto } \\
\text { da vida }\end{array}$ & 0,69 & \multirow{4}{*}{0,61} & \multirow{4}{*}{ Capital cultural } \\
\hline & Para ter uma carreira, precisa estudar muito & 0,64 & & \\
\hline & Eu gosto muito de estudar & 0,63 & & \\
\hline & Se eu for um bom aluno, com certeza terei uma boa carreira & 0,60 & & \\
\hline \multirow{3}{*}{$\begin{array}{l}\text { Grande incerteza } \\
\text { sobre a escolha } \\
\text { profissional }\end{array}$} & Estou indeciso quanto à escolha da carreira que pretendo seguir & 0,77 & \multirow{3}{*}{0,61} & \multirow{3}{*}{ Capital social } \\
\hline & Tenho medo de escolher uma carreira e não gostar & 0,66 & & \\
\hline & $\begin{array}{l}\text { Sinto-me pressionado para escolher o que vou fazer quando terminar } \\
\text { o ensino médio }\end{array}$ & 0,60 & & \\
\hline \multirow{2}{*}{$\begin{array}{l}\text { O trabalhar é uma } \\
\text { necessidade atual }\end{array}$} & Hoje em dia, eu preciso trabalhar & 0,79 & \multirow{2}{*}{0,60} & \multirow{2}{*}{ Capital econômico } \\
\hline & Preciso trabalhar logo que terminar o ensino médio & 0,76 & & \\
\hline \multirow{2}{*}{$\begin{array}{l}\text { O ensino público } \\
\text { me discrimina }\end{array}$} & $\begin{array}{l}\text { É muito difícil passar no vestibular de faculdades públicas fazendo } \\
\text { colégio público }\end{array}$ & 0,72 & \multirow[t]{2}{*}{0,35} & \multirow[t]{2}{*}{ Capital cultural } \\
\hline & Me sinto discriminado por estudar em escola pública & 0,70 & & \\
\hline
\end{tabular}

Fonte: Elaborada pelos autores. 
Diante das dimensões obtidas e através do cálculo da média aritmética das questões de cada fator obtido pela análise fatorial, aplicou-se a análise de agrupamentos, por meio de método hierárquico, distância euclidiana quadrática, padronização por escore Z e algoritmo de Ward para a elaboração dos grupos. A partir de uma análise dos dados agrupados, foi possível nomear esses grupos da seguinte forma: os Decididos (13,4\%); os Orientados (12,3\%); os Inseguros (35,2\%); os Estagnados (19,16\%); os Indecisos (10,1\%); e os Pessimistas (9,7\%).

\section{RESULTADOS E DISCUSSÃO}

Feita a apresentação do percurso metodológico, neste tópico a intenção será apresentar as características de cada um dos seis (6) agrupamentos. Isso permite que a análise dos resultados estatísticos transcenda os aspectos descritivos e possibilite uma compreensão a partir dos capitais (econômico, social e cultural) e dos processos de reprodução das classes sociais.

\section{Os Decididos $(13,4 \%)$}

Entre todos os grupos encontrados, este foi o que apresentou menor grau de incerteza com relação à sua escolha profissional (Fator 4 - capital social) e o que menos associa o ganho financeiro e o status (Fator 1 - capital econômico) à noção de carreira. Observou-se que, para as questões da importância dos estudos (Fator 3 - capital cultural) e da necessidade de trabalho atual (Fator 5 - capital econômico), este grupo apresentou resultados elevados. Obteve a maior pontuação entre todos os grupos no Fator 3 e a segunda maior pontuação no Fator 4. Sobre a presença da família e do trabalho como prioridade (Fator 2 - capital social), o grupo obteve a segunda menor pontuação, ocorrendo o mesmo com a ideia do ensino público como discriminante (Fator 6 - capital cultural). Pela análise das variáveis socioeconômicas, verifica-se que, neste grupo, a maioria mostra-se do gênero feminino (63,3\%), a renda familiar predominante é de até $R \$ 2.640,00(61,75 \%)$ e $26,3 \%$ das pessoas já estão trabalhando.

A reprodução da classe e da família é evidente neste grupo dos Decididos. Este perfil é de jovens extremamente decididos sobre que caminho seguir, no sentido de se tornarem trabalhadores após o término do ensino médio. Eles não teriam problema em alcançar o ensino superior, desde que pudessem conciliar com o trabalho. Assim, o grupo continuaria o estudo se houvesse essa conciliação, pois está disposto a trabalhar. A busca por esse trabalho não está contida em um trabalho mais bem qualificado e que permitirá melhor obtenção de renda, mas na ideia de que se precisa exercer uma atividade remunerada. Com isso, a perspectiva de carreira ou de sucesso na carreira, no sentido de almejar melhores condições de trabalho e vida, não está no horizonte desses jovens. Eles são decididos sobre exercer uma atividade remunerada, porém não em angariar posições superiores e de status social. É um grupo que reproduz o contexto familiar, por ser composto por filhos de trabalhadores assalariados e com baixo nível de escolaridade dos pais.

\section{Os Orientados $(12,3 \%)$}

Entre os grupos encontrados, este foi o que apresentou menor pontuação para a questão da necessidade de trabalho atual (Fator 5 - capital econômico), da discriminação do ensino público (Fator 6 - capital cultural) e da presença da família e da priorização do trabalho em detrimento dos estudos (Fator 2 - capital social). A respeito da questão do ganho financeiro e do status ligado à carreira (Fator 1 - capital econômico) e da incerteza da escolha profissional (Fator 4 - capital social), este grupo apresentou o segundo menor resultado entre todos os outros. Quanto à importância dos estudos (Fator 3 - capital cultural), foi o grupo que apresentou a segunda maior pontuação. Observa-se que a única diferença entre o grupo anterior (os Decididos) e este grupo é que o primeiro prioriza muito os estudos, mas precisa trabalhar, ao passo que este prioriza os estudos e não precisa trabalhar. Pela análise da renda, tem-se que a porcentagem de alunos com renda familiar superior a $\mathrm{R} \$ 4.400,00$ é maior para este grupo $(10,6 \%)$ do que para o grupo anterior $(8,4 \%)$, o que poderia justificar a não necessidade de trabalho do segundo grupo em comparação ao primeiro. A maioria desse grupo também é do gênero feminino $(56,8 \%)$ e $17 \%$ das pessoas já trabalham.

Este grupo, apesar de corresponder a apenas $12 \%$ da amostra, é o que possui uma visão positiva em relação ao ensino superior. É um grupo constituído em sua maioria por mulheres que procuram romper com a condição social através da educação. Isso porque as experiências de êxito e fracasso dentro da família e as experiências dos pares próximos podem estimular os 
integrantes desse grupo a buscarem condições de vida melhores. A maioria possui pais com ensino superior completo. Isso permite uma orientação sobre o que buscar para melhorar a condição social, mas mesmo assim as perspectivas de carreira e de sucesso na carreira estão limitadas à educação como uma forma legítima de trampolim para melhores condições sociais. Mesmo assim, apesar das orientações, é um grupo que mantém a reprodução da classe social à qual pertence. Como almeja o ensino superior, não se preocupa com a discriminação em relação à escola pública.

\section{Os Inseguros $(35,2 \%)$}

Neste grupo, as respostas, em vários fatores, foram intermediárias (Fator 1 - capital econômico; Fator 2 - capital social; e Fator 6 - capital cultural). Nesse caso, o que chamou mais atenção foi sua colocação na questão da importância dos estudos (Fator 3 - capital cultural) e da necessidade de trabalho atual (Fator 5 - capital econômico), que tenderam a pontuações mais elevadas. E também sua inclinação intermediária (neutra) à questão da incerteza da escolha profissional (Fator 4 - capital social). Sobre as características demográficas, a maioria deste grupo é do gênero masculino (52,3\%), a renda familiar mensal está concentrada na faixa até $\mathrm{R} \$ 2.640,00$ (65,47\% - maior proporção entre todos os grupos nessa faixa de renda) e 22,99\% já exercem algum tipo de atividade remunerada.

Este grupo foi chamado de Os Inseguros, o que corresponde a 35\% do total da amostra (maior grupo), pois o contexto social de vida os leva a essa condição de insegurança. São jovens que precisam de dinheiro, mas gostariam de poder escolher uma profissão pela vocação, e não por necessidade financeira. Ficam no dilema da sobrevivência e da felicidade na escolha. A perspectiva de carreira está atrelada aos aspectos objetivos que a carreira poderá proporcionar, como salário e promoções, mas este grupo não almeja galgar essas posições via educação. $O$ fato aqui é a necessidade de angariar recursos financeiros para o sustento da família. No geral, os pais não possuem ensino superior. As dificuldades financeiras e sociais vividas pela família estão manifestadas na necessidade de buscar ganhos financeiros mais do que uma profissão pela vocação.

\section{Os Estagnados (19,2\%)}

Entre os grupos encontrados, este foi o que apresentou menor pontuação para a questão da importância dos estudos (Fator 3 - capital cultural). Eles apresentaram resultados baixos com relação à questão da incerteza (Fator 4 - capital social), da presença da família e da priorização do trabalho em detrimentos dos estudos (Fator 2 - capital social) e do ensino público como discriminante (Fator 6 - capital cultural). Enquanto isso, demostraram resultados intermediários (neutros) para a questão da necessidade de trabalho atual (Fator 5 - capital econômico) e do ganho financeiro e do status associados à carreira (Fator 1 - capital econômico). Sobre as variáveis sociodemográficas, a maioria deste grupo é do gênero masculino $(63,2 \%)$, a renda também se concentra na faixa de até $R \$ 2.640,00$ e 26,51\% já exercem algum tipo de atividade remunerada (maior proporção observada entre todos os grupos).

Este grupo foi o que mais reproduziu a condição familiar e por esse motivo foi nomeado como Os Estagnados. Estes alunos não observam o ensino como forma de conduzi-los à saída da condição social em que vivem. Além disso, não possuem perspectivas de carreira promissoras e não almejam ganhos superiores provenientes de uma profissão. Neste grupo, há um nível acentuado de dificuldade em sair da condição social vivida. Eles possuem pouquíssimo capital cultural e baixo capital econômico e estão totalmente acoplados ao capital social de sua classe de origem. É o segundo maior grupo da amostra, com cerca de $19 \%$ dos respondentes, o que evidencia a dificuldade da escola pública brasileira em gerar melhores perspectivas de carreiras.

\section{Os Indecisos $(10,1 \%)$}

Entre todos os grupos, este foi o que apresentou maior pontuação com relação à incerteza da escolha profissional (Fator 4 capital social), à questão da remuneração financeira e do status como determinantes da carreira (Fator 1 - capital econômico), à presença familiar e da priorização do trabalho em detrimento dos estudos (Fator 2 - capital social) e à necessidade de trabalho atual (Fator 5 - capital econômico). Com resultados elevados para os Fatores 1, 4 e 5, apesar da maior pontuação, este grupo teve resultados que tenderam à parcela discordante da escala ao Fator 2 - capital social. Neste grupo, os alunos também demostraram considerar o estudo importante (Fator 4 - capital social), porém foi a terceira menor nota para esse quesito em comparação com os outros grupos, além de ter apresentado escore intermediário (neutro) para a questão da discriminação do ensino público (Fator 6 - capital cultural). Sobre as características sociodemográficas deste grupo, ele conta com maioria do gênero masculino (59,2\%), a faixa de renda predominante é de até $\mathrm{R} \$ 2.640,00(56,88 \%)$ e $24,02 \%$ já trabalham. 
Com base nessas constatações, tem-se que a incerteza sobre as escolhas de carreira deste grupo é bem elevada. Como ele também apresentou grande necessidade de trabalho atual, tem-se que essa incerteza pode decorrer da ansiedade de trabalhar logo, ou seja, como se a pressão para escolha fosse mais elevada. Tal situação também pode ser refletida pelo fato de este grupo também se preocupar bastante com a questão da remuneração financeira e do status ligados a seu desenvolvimento de carreira.

Este grupo reverbera bem as considerações de Bourdieu e Paresson (1975), pois o ganho financeiro é mais importante do que a escolha de uma carreira promissora. Para tanto, o intuito é terminar o ensino médio e entrar no mercado sem, necessariamente, saber ao certo que profissão ou trabalho seguir. Aqui, dá-se a impressão de que qualquer trabalho ou emprego é ideal. Isso mostra, novamente, que o ensino possui um papel marginal da saída da condição social. A preocupação com o ensino só será importante após a entrada no mercado de trabalho, mais como complemento do trabalho desenvolvido (curso técnico) do que como progresso na carreira (curso superior).

\section{Os Pessimistas $(9,8 \%)$}

Entre todos os grupos, este foi o que apresentou maior pontuação para a questão da discriminação ocasionada pelo ensino público (Fator 6 - capital cultural). Enquanto isso, com relação às outras dimensões, nenhum outro valor tendeu aos extremos. A questão da importância do estudo (Fator 3 - capital cultural) obteve resultado elevado, mas foi a segunda menor pontuação, entre os grupos, para essa dimensão. A necessidade de trabalho atual (Fator 5 - capital econômico) e a incerteza sobre a escolha profissional (Fator 4 - capital social) apresentaram valores intermediários (neutros). Observa-se situação similar no caso do Fator 4 (capital social) em que, apesar de ter apresentado escore intermediário (neutro), a pontuação deste grupo foi a segunda maior entre todos os outros. Sobre as características sociodemográficas do grupo, ele conta com maioria do gênero feminino $(61,4 \%)$ e a faixa de renda predominante é de até $\mathrm{R} \$ 1.640,00$ (56,49\%). No entanto, é o grupo que obteve maior pontuação para a faixa de mais de $\mathrm{R} \$ 4.401,00$ (12,99\%). Destes alunos, 25,39\% já estão exercendo atividades remuneradas.

O que se pode inferir, a partir desse cenário apresentado, é que tais alunos consideram o estudo importante, porém não tanto quanto os dos outros grupos. Eles não possuem uma urgência com relação à necessidade de trabalhar (terceira menor pontuação entre os grupos) e apresentam certo grau de incerteza. Junto a essa situação, eles acreditam que o ensino público dificulta muito sua entrada em uma faculdade pública, o que tem sido um desestímulo a seguir carreiras que necessitem de curso superior. Esse fato está ligado ao processo de massificação do ensino, que tende a gerar a desvalorização dos diplomas escolares. Mas não é só isso: tende a desvalorizar o próprio ensino público como capaz de conduzir a melhores condições sociais. Ainda nesse grupo, estão inseridos indivíduos das classes médias. Talvez por isso o descrédito em relação ao ensino público. Isso explica também o fato de eles não necessitarem decidir sobre a carreira no curto espaço de tempo. É o menor grupo encontrado na amostra, o que mostra um estado de exceção no âmbito do ensino público do município pesquisado.

\section{Os cruzamentos entre as variáveis sociodemográficas e os agrupamentos}

Com o intuito de unir as duas partes do questionário, foram realizados cruzamentos entre as variáveis sociodemográficas e os grupos encontrados. Para uma melhor análise dos resultados e para que não haja viés relacionado à desproporção entre a quantidade de alunos em cada grupo, optou-se pela padronização Qui-quadrado $\left(\chi^{2}\right)$ de todos os dados.

Pela renda familiar mensal dos alunos, observou-se que, nos grupos dos Orientados e dos Pessimistas as rendas familiares são as maiores (renda entre R\$ 4.401,00 a R\$ 13.200,00). Nos grupos dos Decididos e dos Indecisos, as rendas familiares são medianas em relação às rendas familiares maiores e as menores encontradas na pesquisa (renda entre $R \$ 2.641,00$ a $\mathrm{R} \$$ 4.400,00). Já nos grupos dos Inseguros e dos Estagnados, as rendas familiares são as menores (renda de até R\$ 880,00).

Aqui ficam evidentes alguns fatores relacionados à teoria de Bourdieu. O primeiro refere-se ao capital econômico. Os grupos com poder aquisitivo maior ou possuem algum tipo de orientação familiar ou estão pessimistas com o ensino médio público, pois este não permite com que eles alcancem melhores posições sociais. O segundo refere-se ao capital social. Com pais empregados e com posições de trabalhos melhores, observa-se um capital social melhor na orientação sobre o futuro.

Corrobora-se a essa situação o nível de escolaridade dos pais. Verificou-se que o menor nível de escolaridade (ensino fundamental incompleto) tanto para o pai quanto para a mãe desses alunos foi mais significante no grupo dos Inseguros. E o maior nível de escolaridade (ensino superior completo), também para ambos, foi mais significante no grupo dos Orientados. 
A respeito da profissão dos pais, no grupo dos Decididos houve predominância do pai trabalhador na produção de bens e serviços e da mãe na categoria Outros (falecida, afastada, aposentada, pensionista, desaparecida ou aquela que os filhos não a conhecem). No grupo dos Orientados, o pai é trabalhador na área dos serviços administrativos e a mãe, técnica de nível médio. No grupo dos Inseguros, o pai é trabalhador da produção de bens e serviços e a mãe, desempregada. No grupo dos Estagnados, o pai é empresário ou comerciante e a mãe trabalha em ocupações maldefinidas. No grupo dos Indecisos, o pai é autônomo e há predomínio da mãe na categoria de dirigente. E, no grupo dos Pessimistas, ambos (pai e mãe) são enquadrados como profissionais das ciências e das artes.

Essa correlação entre as variáveis sociodemográficas e os agrupamentos evidenciam a condição descrita por Bourdieu e Paresson (1975) de reprodução da família e das classes sociais no âmbito do ensino público. As perspectivas de carreiras e as visões futuras de sucesso na carreira seriam limitadas para todos os grupos constituídos. Além disso, não é o ensino um fator fundamental de mudança na condição social, mas, sim, os capitais (econômico, social e cultural) herdados da família. O capital cultural só tem validade quando observado na família ou no grupo de referência. Assim, os agrupamentos, longe de mostrar realidades completamente diferentes para cada grupo, apresentam realidades bem próximas com baixa margem de manobra. Talvez por isso Bourdieu (1986) preferiu o termo "agente" em detrimento do termo "sujeito", pois, por mais estruturada e herdada que é a condição dos indivíduos, eles ainda possuem um limite de manobra.

\section{CONSIDERAÇÕES FINAIS}

O objetivo deste artigo foi analisar as perspectivas de carreiras dos jovens do ensino médio público de uma cidade do interior de São Paulo, no que tange aos aspectos sociais, familiares, educacionais e culturais. Uma contribuição do artigo foi trazer para a discussão sobre carreira a teoria do sociólogo francês Pierre Bourdieu, que discute o sistema educacional como reprodutor das classes sociais. Sendo o sistema educacional um elemento importante, no âmbito das teorias sobre carreira, no processo de desenvolvimento de carreiras, então compreender tal sistema como reprodutor de classes insere limitações evidentes em quem pode ou não ter uma carreira. São essas possíveis limitações que precisam ser debatidas no âmbito dos estudos sobre carreira, deixando evidentes "carreiras para quem" e "quem pode ter carreira".

A pesquisa realizada com 3.247 jovens do ensino médio de escolas públicas de uma cidade no interior de São Paulo evidenciou que os processos de reprodução das classes sociais são algo evidente e limitam as perspectivas sobre carreiras deles. Para chegar a tal afirmação, foram realizadas as análises de agrupamento e fatorial dos dados coletados a partir de um questionário estruturado. A análise de agrupamentos permitiu identificar seis agrupamentos, que foram nomeados como: Decididos, Orientados, Inseguros, Estagnados, Indecisos e Pessimistas. A análise fatorial possibilitou identificar os capitais (econômico, social e cultural) que influenciam e limitam as perspectivas de carreira dos jovens entrevistados.

Os resultados reforçam as afirmações de Bourdieu de que o sistema educacional é reprodutor dos elementos das classes dominantes, mas também evidencia algumas distinções, quando esses agrupamentos são correlacionados com os fatores sociodemográficos dos jovens participantes da pesquisa. Nesta linha, as diferenças entre as classes sociais ficam evidentes, mostrando que os indivíduos das classes baixas apresentam perspectivas de comportamentos inseguros e estagnados em relação ao que fazer após sair do ensino médio. Aqueles jovens em que a família possui um nível maior de renda representam jovens com perspectivas comportamentais de decisão e indecisão em relação à escolha profissional. Os Decididos querem sair do ensino médio e trabalhar. Os Indecisos também querem trabalhar, mas ainda não sabem o que vão fazer. Por fim, aqueles jovens em que as famílias possuem os níveis mais altos de renda, entre todos os pesquisados, apresentam perspectivas comportamentais de orientados e pessimistas. Os Orientados estão propensos a continuar os estudos e não possuem a necessidade de trabalhar após o término do ensino médio. E os Pessimistas veem de forma negativa o ensino médio público gratuito em relação a uma possível colocação profissional no mercado. 


\section{REFERÊNCIAS}

AKKERMANS, J. et al. It's all about career-skills: effectiveness of a career development intervention for young employees. Human Resource Management, v. 54, n. 4, p. 533-551, 2015.

ARTHUR, M. B. The boundaryless career: a new perspective for organizational inquiry. Journal of Organizational Behavior, v. 15, n. 4, p. 295-306, 1994.

ARTHUR, M. B.; HALL, D. T.; LAWRENCE, B. S. Generating new directions in career theory: The case for a transdisciplinary approach. Handbook of career theory, v. 7, p. 25, 1989.

ARTHUR, M. B.; KHAPOVA, S. N.; WILDEROM, C. P. M. Career success in a boundaryless career world. Journal of Organizational Behavior, v. 26, n. 2, p. 177-202, 2005.

BONAMINO, A. et al. Os efeitos das diferentes formas de capital no desempenho escolar: um estudo à luz de Bourdieu e de Coleman. Revista Brasileira de Educação, v. 15, n. 45, p. 487-499, 2010.

BOURDIEU, P. A gênese dos conceitos de habitus e de campo. In: BOURDIEU, P. O poder simbólico. Rio de Janeiro: BertrandBrasil, 1989.

BOURDIEU, P. Questões de sociologia. Rio de Janeiro: Marco Zero, 1983.

BOURDIEU, P. The forms of capital. In: RICHARDSON, J. Handbook of theory and research for the sociology of education. Westport: Greenwood, 1986.

BOURDIEU, P. The practice of reflexive sociology. In: BOURDIEU, P.; WACQUANT, L. J. D. An invitation to reflexive sociology. Chicago: The University of Chicago Press, 1992.

BOURDIEU, P. The social conditions of the international circulation of ideas. Actes de la recherche en sciences sociales, n. 5, p. 3-8, 2002.

BOURDIEU, P.; PARESSON, J. C. A reprodução: elementos para uma teoria do sistema de ensino. Rio de Janeiro: Francisco Alves, 1975.

CONNOLLY, P.; HEALY, J. Symbolic violence, locality and social class: the educational and career aspirations of 10-11-year-old boys in Belfast. Pedagogy, Culture and Society, v. 12, n. 1, p. 15-33, 2004.

CLARK, B.; JOUBERT, C.; MAUREL, A. The career prospects of overeducated Americans. IZA Journal of Labor Economics, v. 6, n. 1, 2017.

DEFILLIPI, R.; ARTHUR, M. B. The boundaryless career: a competencybased perspective. Journal of Organizational Behavior, v. 15, n. 4, p. 307-24, 1994.

DENAULT, A. S. et al. Extracurricular activities and career indecision: A look at the mediating role of vocational exploration. Journal of Vocational Behavior, v. 110, p. 43-53, 2019.

GALE, T.; PARKER, S. Calculating student aspiration: Bourdieu, spatiality and the politics of recognition. Cambridge Journal of Education, v. 45, n. 1, p. 81-96, 2015.
HAIR, J. et al. Análise multivariada de dados. 6. ed. Porto Alegre: Bookman, 2009.

HALL, D. T. Careers in and out of organizations. New York: Sage, 2002.

HARRINGTON, B.; HALL, D. T. Career management \& work-life integration: using self-assessment to navigate contemporary careers. New York: Sage, 2007.

LEHMANN, W. Working-class students, habitus, and the development of student roles: a Canadian case study. British Journal of Sociology of Education, v. 33, n. 4, p. 527-546, 2012.

NEWMAN, B. K. Career change for those over 40: Critical issues and insights. The Career Development Quarterly, v. 44, n. 1, p. 64, 1995.

NOGUEIRA, C. M. M.; NOGUEIRA, M. A. A sociologia da educação de Pierre Bourdieu: limites e contribuições. Educação \& Sociedade, v. 23, n. 78, p. 15-35, 2002.

PEIPERL, M.; BARUCH, Y. Back to square zero: the post-corporate career. Organizational Dynamics, v. 25, n. 4, p. 7-22, 1997.

RIUTORT, P. Compêndio de sociologia. São Paulo: Paulus, 2008.

ROGNSTAD, M. K.; AASLAND, O.; GRANUM, V. How do nursing students regard their future career? Career preferences in the post-modern society. Nurse Education Today, v. 24, n. 7, p. 493-500, 2004.

SUTIN, A. R. et al. Personality and career success: Concurrent and longitudinal relations. European Journal of Personality, v. 23, n. 2, p. 71-84, 2009.

THIRY-CHERQUES, H. Pierre Bourdieu: a teoria na prática. Revista de Administração Pública, v. 40, n. 1, p. 27-53, 2006.

THOMPSON, M. N. et al. Integrating job loss, unemployment, and reemployment with Social Cognitive Career Theory. Journal of Career Assessment, v. 25, n. 1, p. 40-57, 2017.

VALLE, I. R. O lugar da educação (escolar) na sociologia de Pierre Bourdieu. Revista Diálogo Educacional, v. 13, n. 38, p. 411437, 2013.

VARGAS, M. L. F. Estudos sobre o funcionamento do sistema de ensino: da reprodução das desigualdades sociais ao efeito escola. Cadernos de Educação, v. 32, p. 105-122, 2009.

WRIGHT, S. L.; JENKINS-GUARNIERI, M. A.; MURDOCK, J. L. Career development among first-year college students: college self-efficacy, student persistence, and academic success. Journal of Career Development, v. 40, n. 4, p. 292-310, 2013.

ZELLWEGER, T.; SIEGER, P.; HALTER, F. Should I stay or should I go? Career choice intentions of students with family business background. Journal of Business Venturing, v. 26, n. 5, p. 521536, 2011. 
Heliani Berlato

ORCID: https://orcid.org/0000-0003-2480-8293

Doutora em Administração pela Faculdade de Economia, Administração e Contabilidade da Universidade de São Paulo (FEA/USP); Professora associada na Escola Superior de Agricultura "Luiz de Queiroz" da Universidade de São Paulo (ESALQ/USP), Piracicaba - SP, Brasil. E-mail: hberlato@usp.br

\section{Luciano Mendes}

ORCID: https://orcid.org/0000-0002-6159-7184

Doutor em Administração pela Universidade Federal do Rio Grande do Sul (UFRGS); Professor associado na Escola Superior de Agricultura "Luiz de Queiroz" da Universidade de São Paulo (ESALQ/USP), Piracicaba - SP, Brasil. E-mail: mendes@usp.br

\section{Danilo Andretta}

ORCID: https://orcid.org/0000-0003-4139-6550

Mestre em Administração pela Escola Superior de Agricultura "Luiz de Queiroz" da Universidade de São Paulo (ESALQ/USP), Piracicaba - SP, Brasil. E-mail: danilo.andretta@usp.br 